$\therefore \quad: \quad-1+2$ 


\title{
Functional Testing of the Space Station Plasma Contactor
}

\author{
Michael J. Patterson and John A. Hamley" \\ National Aeronautics and Space Administration \\ Lewis Research Center \\ Cleveland, $\mathrm{OH}$ \\ Timothy R. Sarver-Verhey ${ }^{*}$ and George C. Soulas ${ }^{\dagger}$ \\ NYMA Inc. \\ Engineering Services Division \\ Brook Park, OH
}

\begin{abstract}
A plasma contactor system has been baselined for the International Space Station Alpha (ISSA) to control the electrical potentials of surfaces to eliminate/mitigate damaging interactions with the space environment. The system represents a dual-use technology which is direct outgrowth of the NASA electric propulsion program and, in particular, the technology development effort on ion thruster systems. The plasma contactor subsystems include a hollow cathode assembly, a power electronics unit, and an expellant management unit. Under a pre-flight development program these subsystems are being developed to the level of maturity appropriate for transfer to U.S. industry for final development. Development efforts for the hollow cathode assembly include design selection and refinement, validating its required lifetime, and quantifying the cathode performance and interface specifications. To date, cathode components have demonstrated over 10,000 hours lifetime, and a hollow cathode assembly has demonstrated over 3,000 ignitions. Additionally, preliminary integration testing of a hollow cathode assembly with a breadboard power electronics unit has been completed. This paper discusses test results and the development status of the plasma contactor subsystems for ISSA, and in particular, the hollow cathode assembly.
\end{abstract}

\section{Introduction}

The International Space Station Alpha (ISSA) power system is designed with high voltage solar arrays which operate at output voltages of typically 140-160 volts, and is configured with a "negative ground" that electrically ties the habitat modules, structure, and radiators to the negative tap of the solar arrays. This electrical configuration and the plasma current balance that results will cause the habitat modules, structure, and radiators to float to voltages as large as $-120 \mathrm{~V}$ with respect to the ambient space plasma. ${ }^{1}$ As a result of these large negative floating potentials, there exists the potential for deleterious interactions of ISSA with the space plasma. These interactions may include arcing through insulating surfaces and sputtering of conductive surfaces due to acceleration of ions by the spacecraft plasma sheath. Both of these processes result in changes in surface material properties, destruction of coatings, and contami- nation of surfaces due to redeposition.

The space experiment SAMPIE (for Solar Array Module Plasma Interactions Experiment) was recently flown on the Space Transportation System STS-62 and provided validation of the theoretical models of spacecraft charging which were used to predict the station floating potentials. The flight data from this experiment, which quantified the current collection to station solar array elements, confirmed the need for a plasma contactor to control the potential of the space station. ${ }^{2}$

Based on it's potential-effectiveness, a decision was made to baseline a plasma contactor system on ISSA as the solution to alleviate plasma interactions. ${ }^{3}$ NASA has therefore initiated a plasma contactor development program as part of the ISSA electrical power system.

There are several major derived operational requirements for the station plasma contactor system which include capability to control station potential to within 20

Aerospace Engineer, Member AlAA

${ }^{+}$Aerospace Engineer 
volts of space plasma potential; emit electron currents up to $10 \mathrm{~A}$ under dynamic and variable conditions; operate for up to 17,500 hours without degradation; minimize consumables; be single-fault tolerant in design; be compatible with all space station utilities; be robotically serviceable; and incorporate health monitoring instrumentation, including instrumentation to measure the plasma return current. A more detailed discussion of these requirements may be found in Reference 4 .

For the ISSA application, efficient and rapid emission of high electron currents is required by the plasma contactor system under conditions of variable and uncertain current demand. A hollow cathode plasma source is well suited for this application and was therefore selected as the design approach for the station plasma contactor system.'

Active emission to the space plasma of electron current at least matching the net electron current collected on the station solar arrays (referred to as "clamping" mode) is required for only a small portion of the station orbital period. This period is during approximately one-third of the orbit, from dawn through noon when the solar arrays are illuminated, generate power, and face in the ram direction. During the remainder of the orbital period the hollow cathode plasma source may be either operated in an "idle" mode or turned off. A baseline approach of keeping the station hollow cathode plasma source on continuously throughout the orbit has been selected."

This paper discusses the test results and development status of the plasma contactor subsystems for ISSA, and in particular, the hollow cathode plasma source.

\section{System Design}

The ISSA plasma contactor system (PCS) consists of four subsystems including a hollow cathode assembly (HCA), a power electronics unit (PEU), an expellant management unit (EMU), and an orbit replaceable unit (ORU). Figure 1 shows a conceptual design for the plasma contactor system. The hollow cathode assembly, or HCA, is the active electron emitter. It consists of a hollow cathode, a low-work function insert for electron emission, an anode, a heater, and an electrical isolator. The design approach selected for the station HCA is an enclosed-keeper geometry, operating on xenon gas."

The power electronics unit, or PEU, conditions power from the ISSA 120 VDC main power bus, converting it to the levels necessary for the plasma contactor system. It consists of the power supplies for operation of the hollow cathode and the gas feed system valves, and a controller to provide a command and telemetry interface to the station data system.

The expellant management unit, or EMU, consists of a high-pressure gas storage tank, xenon gas, and gas feed system components including lines, valves, and regulators. The EMU stores the xenon as a gas under high pressure, and controls and regulates its flow to the HCA.
The fourth subsystem, the ORU, is a standard station avionics box which provides the structural, thermal, electrical, and data interfaces, as well as providing micrometeoroid protection. Table 1 lists the technology issues with each of the subsystems and identifies their associated functions.

\section{Test Apparatus and Procedure}

Development activities and tests of the station PCS subsystems are underway at NASA Lewis Research Center These activities are being conducted to establish requirements and specifications for the flight system, and to validate these requirements and specifications via longduration lifetests under appropriate environmental and operational conditions.

The details of the HCA design are described in the following section, while the design of the PEU used in integration testing can be found in References 6 and 7 . The electrical configuration of the HCA tests is shown in the schematic of Figure 2. Two power supplies are used for the operation of the HCA including the heater supply (used in starting only), and the anode power supply. In steady-state operation, an electron current of fixed magnitude (referred to here as the anode current) passes from the HCA cathode to anode and is circulated through the anode supply. For most performance tests, commercial power supplies were used to operate the HCA.

An additional power supply, labeled as the bias supply, is used to vary the potential between the HCA and facility ground, and simulates the potential established between space station structures and space plasma. To quantify the electron emission capability of the HCA, the hollow cathode of the HCA is biased negative with respect to facility ground, causing electrons produced by the HCA to be emitted from it and collected at the vacuum tank walls. This electron current is referred to here as the contactor emission current, and is, in space, equivalent to the electron current emitted by the contactor which offsets that collected by the station high voltage solar arrays. The potential difference between HCA cathode and facility ground is referred to as the clamping voltage. When the contactor emission current is zero but the HCA cathode is emitting to the anode, the HCA is operating in an idle mode. When the contactor emission current is non-zero, the HCA is operating in a clamping mode.

For performance and lifetime characterizations of the $\mathrm{HCA}$, and integration testing of the HCA with the power electronics unit, several vacuum facilities were construct$\mathrm{ed}$, and these are described in detail in Reference 5. Two of the primary facilities are described briefly here.

The characterizations of the steady-state operation of the HCA and integration tests of the HCA with the power electronics unit were conducted in the plasma contactor system integration stand shown in Fig. 3. This vacuum 
facility, fabricated of aluminum, is $2.1 \mathrm{~m}$ in diameter and $4.3 \mathrm{~m}$ long. The pumping train includes a two-stage blower system backed up by a roughing pump. The chamber is equipped with four $0.9 \mathrm{~m}$ diameter helium refrigerator cryopumps which together provide a xenon pumping speed of approximately $60,000 \mathrm{l} / \mathrm{s}$. The chamber has several test ports, one of which is $0.9 \mathrm{~m}$ in diameter with a $1.1 \mathrm{~m}$ long spool piece and an isolation valve for installation of the HCA into the main chamber.

Assessments of the HCA to quantify its electron emission capability and its optical and radiated emissions were performed in a large vacuum facility which is approximately $4.6 \mathrm{~m}$ in diameter by $18.3 \mathrm{~m}$ long and has a xenon pumping speed of approximately $340,000 \mathrm{l} / \mathrm{s}$, provided by twenty $0.9 \mathrm{~m}$ diameter oil diffusion pumps and a $15 \mathrm{~K}$ helium cryosurface of approximately $28 \mathrm{~m}^{2}$ area.

It is noteworthy that there are environmental and scaling effects which can impact the electron emission characteristics of the HCA, and these effects become more pronounced at high contactor emission currents. These effects include the proximity, geometry, and surface condition of the extemal anode simulating the current draw to the space plasma. To mitigate these effects and obtain what is believed are space-like conditions, all test results reported here were obtained with a large area anode ( $100 \mathrm{~m}^{2}$ ), whose surfaces were in excess of $2 \mathrm{~m}$ from the HCA.

\section{Hollow Cathode Assembly}

In the present development phase the HCA for ISSA will be brought to an engineering status appropriate for transfer to industry for final development. This section describes the design of the HCA, and discusses preliminary results obtained from performance and lifetime tests. In the course of this development program, performance and lifetime assessments will be conducted on approximately 3 prototype HCA units, and 15 engineering model HCA units. Up to an additional 10 units of a modified design will be fabricated and tested in the event that design modifications, as identified from lifetime or vibration tests, are required.

\section{Design}

As previously mentioned, the design approach selected for the station HCA is an enclosed-keeper geometry, operating on xenon gas. Prior to this selection, several alternative hollow cathode plasma source designs were investigated, including ring-cusp type sources. While a discussion of all the criteria used in the selection of the baseline HCA design is beyond the scope of this paper (see Reference 4 for a detailed discussion) a few observations are made here. No significant difference in the xenon flow rate requirement was observed for any of the various hollow cathode plasma source designs investigat- ed. This is because the contactor emission current itself contributes significantly to the source ionization efficiency. A second observation was that the magnitude of the clamping voltage varies directly with the HCA anode voltage.

The primary considerations in HCA selection were to design a HCA which satisfies the potential control requirement ( $\leq 20$ volts clamping voltage) and maximizes expectations for long life. Based on these considerations, an enclosed-keeper hollow cathode design approach was selected.

The ISSA HCA design consists of a hollow cathode, an anode, a heater, an insulator, and an electrical isolator. The hollow cathode itself consists of a refractory alloy tube with an orifice plate welded on one end. The tube is several millimeters in diameter, while the orifice in the plate is a fraction of a millimeter in diameter. An insert, which is located within the hollow cathode, serves as a low-work function electron source, and is electrically connected to the tube. A heater, used to raise the temperature of the cathode during activation and to facilitate ignition, surrounds the downstream end of the hollow cathode tube.

The HCA incorporates a cylindrical anode which surrounds the hollow cathode in close proximity. The anode is referred to as the keeper as it maintains, or keeps, the cathode emitting during conditions when no external emission current is demanded. The anode is described as enclosed because it completely surrounds the hollow cathode except for a single aperture directly downstream of the hollow cathode orifice. This design is more efficient than an open-keeper geometry because of the higher internal pressures in the cathode/keeper region.

Upstream of the HCA cathode tube is an electrical isolator which isolates the HCA from ISSA structure. This allows the connection from the HCA cathode to the station single point ground to be made via cable, and the contactor emission current can then be monitored by instrumentation within the power electronics unit.

An engineering model design of the HCA has been completed and several units have been fabricated and are under test. The HCA mass, less power cable and connector, is approximately $125 \mathrm{~g}(4.4 \mathrm{oz}$.). It is cylindrical in shape, and has a length of approximately $11.5 \mathrm{~cm}$ and maximum diameter of approximately $2.8 \mathrm{~cm}$. The HCA has three interfaces to the plasma contactor system, including a mechanical attachment point to the ORU, a single xenon gas line to the EMU, and a 3-conductor electrical cable to the PEU. It's design is compatible with operation up to $10 \mathrm{~A}$ electron emission, with anticipation of a two-year lifetime. A HCA, along with a breadboard PEU, is shown in Figure 4. Design and performance parameters for the HCA are listed in Table 2.

\section{Performance}


The performance of several prototypes and engineering model HCA's of the design described previously have been characterized, and results from these tests are summarized in this section.

Ignition - Although continuous operation of the HCA is anticipated, a number of power interruptions to the plasma contactor system during the station assembly process may occur which would require restarting the HCA. Additionally, as a mission critical system aboard a crewed vehicle, the HCA ignition process must be understood and repeatedly demonstrated on a number of test articles to establish confidence in the selected approach.

To define and verify conditions for HCA ignition, a test stand was developed and testing was initiated. ${ }^{8}$ Preliminary tests were conducted on a prototype HCA to define the conditions necessary for reliable ignition including the heater input power, pre-heat time, xenon cathode flow rate, and ignition pulse magnitude and rise-time.

Results from these definition tests indicated that reliable ignition could be achieved at heater input power levels in the power range validated by prior heater lifetests ${ }^{9}$ (approximately 55 watts), within 300 seconds of energizing the heater, and at the nominal flow rates anticipated for steady-state operation of the HCA. These tests were conducted at a peak pulse amplitude of approximately 300 volts, and pulse duration of approximately 20 microseconds.

Subsequent to these definition tests, a long-duration cyclic ignition test on a prototype HCA was performed to validate the ignition requirements. This test consisted of repeating a 20 minute cycle which consisted of a 5 minute cathode pre-heat, an ignition, a 5 minute operation of the HCA in a steady-state idle mode, and a 10 minute cool-down period. This ignition cycle subjects the HCA to temperature variations from approximately $300 \mathrm{C}$ to $1100 \mathrm{C}$.

More than 3300 sequential HCA ignitions were demonstrated on the prototype HCA without a single ignition failure, and the test was voluntarily terminated. Subsequent testing with an engineering model version of the HCA was initiated, and to date more than 500 sequential ignitions have been demonstrated without a single ignition failure. Additional ignition testing is anticipated, in order to demonstrate unit-to-unit repeatability with multiple HCA units. A more detailed discussion of the results of the ignition tests can be found in a companion paper. $^{\text {s }}$

Idle mode operation - The majority of the time, approximately two-thirds of the orbital period, the HCA will be operated in what is termed an idle mode. In this condition, the HCA is operated at a fixed anode current of 2.0 $A$. This current level was selected to maintain the hollow cathode operating temperature in the range of 850-1150 degrees centigrade over the full range of contactor emission currents of 0 to $10 \mathrm{~A}$. This rather high current reduces the total required hollow cathode emission range to a $6: 1$ variation (from 2 to 12 amperes).

In idle mode operation, the static and dynamic impedance of the anode discharge were evaluated at xenon flow rates and currents which bracket the nominal operating envelope for the HCA. These tests were conducted to quantify unit-to-unit dispersions, and to characterize the PEU and EMU interface specifications and stability envelope.

Figure 5 shows the variation in $\mathrm{HCA}$ anode voltage with variation in the xenon gas flow rate, for an anode current of $2.0 \mathrm{~A}$ operating in idle mode (zero contactor emission current). As indicated, the anode voltage decreases with increasing xenon flow rate. By observation of the HCA plasma plume, and measurement of the AC component of the anode current and voltage, it was evident that the HCA was operating in "plume"10 mode for flow rates below about $4.8 \mathrm{sccm}$. Under these conditions, a luminous plasma plume extended downstream of the plane of the enclosed keeper anode, and the anode voltage noise was of the order of 8 volts peak-topeak at a frequency of about $500 \mathrm{kHz}$.

At flow rates above about $4.8 \mathrm{sccm}$, the HCA operates in a quiet spot mode, with a peak-to-peak anode voltage noise of less than 1 volt at frequencies above $1 \mathrm{MHz}$. Increasing the anode current above $2.0 \mathrm{~A}$, or biasing the HCA to emit a net electron current shifts the characteristic of Fig. 5 to lower flow rates and hence reduces the plume-spot transition flow rate.

Figure 6 shows the HCA anode voltage as a function of anode current (from 1.75 A to $2.25 \mathrm{~A}$ ) for several xenon flow rates over the range of interest. These data display the typical negative slope volt-amp characteristic of a plasma discharge. As indicated, for anode currents below $2.0 \mathrm{~A}$, the HCA slips into plume mode operation at flow rates below about $5.2 \mathrm{sccm}$. Above this flow rate, the HCA operates in a quiet spot mode independent of the value of anode current.

The anode voltages identified in Figs. 5 and 6 are typically repeatable to within approximately $0.2 \mathrm{~V}$ for a single HCA unit, and to within approximately $1 \mathrm{~V}$ from unit-to-unit. Typical input power levels for the HCA are approximately 28 watts at $6.0 \mathrm{sccm}$, and approximately 26 watts at $7.5 \mathrm{sccm}$, with $2.0 \mathrm{~A}$ anode current.

Clamping mode operation - As mentioned previously, the HCA actively emits electron current to the space plasma only during a small portion of the station orbital period. This period is approximately for one-third of the orbit, from dawn through noon when the solar arrays are illuminated, generate power, and face in the ram direction. During this period, the HCA must emit an electron current to the space plasma at least matching the net electron current collected on the station solar arrays, and 
do so at a potential difference of $\leq 20$ volts (between HCA cathode and space plasma potential) at all emisșion current levels up to $10 \mathrm{~A}$.

Figure 7 shows the typical emission characteristics for the HCA as a function of xenon flow rate. As indicated, the HCA exhibits low clamping voltages ( 20 volts) for xenon mass flow rates down to about $5.3 \mathrm{sccm}$. Below this flow rate the clamping voltage increases above 20 volts for emission currents greater than 2 amperes, but then collapses above 5 amperes contactor emission current due to gas breakdown. At about $3.8 \mathrm{sccm}$, the electron emission current is limited by the gas flow rate, and the clamping voltage rapidly increases above 20 volts for emission currents greater than approximately $1.8 \mathrm{~A}$.

Figure 8 shows the variation in HCA input power with emission current, and it indicates approximately a $36 \%$ reduction in power going from 0 to 5 A contactor emission current. This is due to a corresponding reduction in anode voltage experienced with increased net hollow cathode emission.

\section{Lifetime}

This section discusses preliminary test results obtained to evaluate the lifetime capability of the hollow cathode components and assembly.

Component weartests - The primary emphases in component lifetesting to date has been in elimination of contamination effects and hollow cathode heater fabrication. The former is to develop and validate procedures to eliminate contamination effects as the life-limiting agent for xenon hollow cathodes. This effort was motivated by recent failures of hollow cathodes in the United States, Europe, and Asia which have apparently been primarily due to inadequate procedures to control contamination during fabrication, assembly, testing, storage, handling, and operation of the cathodes. Prior to initiation of the hardware development program for space station, only one extended-duration test of a xenon hollow cathode at high $(>1 \mathrm{~A})$ emission currents had been reported which had not suffered large deviations in performance which were likely attributable to contamination. "

On-going wear tests appear to have validated these procedures. A xenon hollow cathode, of the design employed in the space station HCA, has demonstrated to date approximately 10,000 hours of steady-state operation at $12 \mathrm{~A}$ emission current. ${ }^{12}$ The test is progressing uneventfully with negligible change in parameters critical to lifetime, and with no significant changes in the cathode starting characteristics. This test is approximately 20 times longer than any previous test which has not shown performance variations attributable to contamination, and is planned to continue to at least $17,500 \mathrm{~h}$.

Four hollow cathodes recently completed a concurrent 2000 hour weartest, with all cathodes operating at a steady-state emission current of $10 \mathrm{~A}^{13}$ Two of the cathodes employed active gettering systems incorporated in the xenon feed system to remove oxide-bearing compounds, and 2 cathodes operated without gettering systems. Excellent unit-to-unit repeatability was observed from externally-measured parameters (cathode tip temperature, and voltages, for example), and no variations in performance attributable to insert contamination were observed with any of the cathodes. Figure 9 shows the anode voltage (tested in a planar diode geometry) for the 4 cathodes as a function of time. This weartest verified procedures, demonstrated transportability of results between test stands, and provided quantification of contamination control requirements imposed on the EMU. Subsequent to the weartest, in-situ analyses of the xenon gas at point-of-use were conducted to quantify the levels of contaminants, and these values will be used as guidelines for defining flight feed system requirements.

Work is progressing under contract at the Georgia Technology Research Institute (GTRI) to define conditions for storage and handling of the HCA, and to define fabrication and inspection procedures for procurement of the flight HCA insert. One objective of the GTRI effort is to provide quantitative information regarding the interaction of the low work function impregnated electron emitter of the HCA with the ambient environment in which it is manufactured, handled, assembled, and stored. These studies indicate that the negative consequences of the exposure of the cathode insert to ambient conditions (e.g., hydration) may be fully reversible via adequate hard vacuum exposure, and that there may be the potential for long-term exposure of the cathodes. These results will be experimentally evaluated at NASA Lewis with engineering model hardware.

The heater design used in the HCA has also undergone a series of weartests. ${ }^{14,15}$ Several engineering model units have been fabricated and tested in a cyclic on/off mode. A total of 9 have been processed for component weartesting, of which 5 have accumulated more than 6000 thermal cycles, simulating $6000 \mathrm{HCA}$ restarts. Figure 10 shows the variation in peak input power versus cycle number for several heaters. Eleven other units have been integrated with engineering model hollow cathode assemblies, and other plasma sources, and 3 of these have completed a 150 cycle performance acceptance/burn-in test.

Lifetests of HCA - Lifetesting of multiple engineering model hollow cathode assemblies will be initiated shortly under conditions simulating the time-dependent emission current profiles expected on orbit. These tests will be used to verify a $17,500 \mathrm{~h}$ lifetime capability of the HCA. Figure 11 shows a schematic representation of the lifetest. The HCA will be operated continuous with an anode discharge, and it will emit an additional electron current to an external anode, simulating the current drawn to the space plasma, on regular intervals duplicating the ISSA 


\section{FUNCTIONAL TESTING OF THE SPACE STATION PLASMA CONTACTOR}

orbit emission requirements.

\section{Space Station Compatibility}

The HCA was tested in conjunction with the breadboard PEU to characterize the HCA radiated electromagnetic emissions. The procedures used for the EMI tests were based on MIL-STD-462, and the test and results are described in detail elsewhere. ${ }^{4}$ The measurements indicated that the HCA emissions for both idle mode and clamping modes were within the SSP 30237 exterior equipment EMI specification for frequencies > $4 \mathrm{MHz}$, while broadband noise and PEU switching hamonics exceeded the SSP 30237 specifications by up to $20 \mathrm{~dB}$ and $30 \mathrm{~dB}$ respectively, for frequencies $\leq 4 \mathrm{MHz}$. Optical emissions in the 3000 - 9000 Angstrom wavelength range were also quantified to evaluate the HCA as an astronaut ocular hazard, and to assess its potential to interfere with station navigational aids and space experiments. Spectra were obtained at both the idle mode zero emission current condition, and at a clamping mode of 2.5 A emission, and the extrapolated total emissive power (side view) for these conditions was estimated to be $(1$ $\mathrm{mW}$ in idle mode, and approximately $20 \mathrm{~mW}$ in clamping mode. Based on these results, it appears that the HCA is unlikely to pose an ocular hazard or to interfere with station navigational aids or experiments.

\section{Power Electronics Unit}

Several breadboard PEUs have been fabricated, and detailed integration testing of a PEU has been completed with a $\mathrm{HCA}^{7}$ These tests were conducted to evaluate the HCA electrical load characteristics to define the PEU/HCA interface, and they demonstrated stable operation of the PEU in all operating regimes of the HCA, including ignition, and steady-state operation of the heater and anode discharge. Additional integration tests with several engineering model HCA units will be conducted to assess unit-to-unit repeatability. The PEU/HCA design will then be validated via a long-duration ( $\geq 2500 \mathrm{~h}$ ) weartest in which the PEU will execute all HCA operations in an autonomous fashion.

\section{Expellant Management Unit}

The expellant management unit (EMU) will be brought to breadboard level in this pre-flight effort. To date, the activities in the EMU effort have been focussed in definition of the contamination limits in the xenon gas reaching the HCA, and definition of the xenon flow control requirements for both ignition and steady-state operation. These requirements have been established using laboratory-type xenon feed systems. A breadboard xenon system incorporating flight qualified components is now in design, and it will be used to verify transportability of the procedures developed with the laboratory systems to obtain the required xenon purity and flow control. The breadboard EMU will then be integrated with the PEU and an engineering model $\mathrm{HCA}$, and a long duration $(\geq$ $2500 \mathrm{~h}$ ) weartest will be conducted to validate the EMU/HCA interface specifications.

\section{Concluding Remarks}

The International Space Station Alpha (ISSA) has baselined a plasma contactor system for potential control of space station structures to mitigate possible damaging interactions with the space plasma. NASA has been directed to initiate a plasma contactor development program as a part of the station electrical power system. Under this program, key subsystems for the plasma contactor are being brought to an appropriate level for transfer to U.S. industry for final development.

Progress in the development of the plasma contactor has been made in key areas. Several prototype and engineering model hollow cathode assemblies have been fabricated, and their performance has been assessed. Conditions for reliable HCA ignition have been defined, and verified via long-duration testing. Ignition tests conducted to date include a 3300 -sequential ignition with a prototype HCA, and a 500-sequential ignition test with an engineering model HCA, both without ignition failure.

The static and dynamic impedance of the HCA anode discharge were quantified under both idle and clamping mode operation, at xenon flow rates and currents which bracket it's nominal operating envelope. These tests were conducted to quantify the operation of the device permitting unit-to-unit measurements of dispersion, and characterization of the PEU and EMU interface specifications and stability envelope. Typical input power levels for steady-state idle mode operation of the HCA are approximately 28 watts at $6.0 \mathrm{sccm}$, and approximately 26 watts at $7.5 \mathrm{sccm}$, with $2.0 \mathrm{~A}$ anode current. Clamping mode operation of the HCA was examined for emission currents up to $10 \mathrm{~A}$. The HCA exhibited low clamping voltages ( $(20$ volts) for xenon mass flow rates as low as about 5.3 sccm.

Preliminary test results were obtained to evaluate the lifetime capability of the hollow cathode components and assembly. The primary emphasis in component lifetesting was in two areas; elimination of contamination effects, and hollow cathode heater fabrication. The former is to develop and validate procedures and protocols to eliminate contamination effects as the life-limiting agent for xenon hollow cathodes. A xenon hollow cathode, of the design employed in the space station HCA, has demonstrated to date approximately 10,000 hours of steady-state operation at $12 \mathrm{~A}$ emission current. The test is progressing uneventfully with negligible change in parameters critical to lifetime. Additional testing of four hollow cathodes to 2000 hours verified procedures, demonstrated transportability of results between test stands, and provided quantification of contamination control requirements imposed on the xenon expellant management unit.

The heater design used in the HCA has also undergone 
a series of weartests. A total of 9 units have been processed for component weartesting, of which 5 have accumulated more than 6000 thermal on/off cycles, simulating $6000 \mathrm{HCA}$ restarts.

Lifetesting of multiple engineering model hollow cathode assemblies will be initiated shortly under conditions simulating the time-dependent emission current profiles expected on orbit. These tests will be used to verify a $17,500 \mathrm{~h}$ lifetime capability of the HCA.

Several breadboard PEU units have been fabricated, and detailed integration testing of a PEU was completed with a HCA. These tests demonstrated stable operation of the PEU in all operating regimes of the HCA, including ignition, and steady-state operation of the heater and anode discharge. Additional integration tests with several engineering model HCA units will be conducted to assess unit-to-unit repeatability.

A breadboard xenon system incorporating flight qualified components is now in design, and it will be used to verify transportability of the procedures developed with the laboratory systems to obtain the required xenon purity and flow control. This breadboard EMU will then be integrated with the power electronics unit and an engineering model HCA, and a long duration ( $\geq 2500 \mathrm{~h}$ ) weartest will be conducted to validate the EMU/HCA and PEU/HCA interface specifications.

\section{Acknowledgements}

The fabrication and test support provided by Robert Butler, Ralph Jacko, George Jacynycz, Fred Jent, Bernard Loyer, Craig Nelson, Mike Pastel, and Eugene Pleban, and operations engineering support provided by James Zakany, are gratefully acknowledged.

\section{References}

'Katz, I., personal communication, S-Cubed Division of Maxwell Labs, San Diego, CA, October 1992.

${ }^{2}$ Ferguson, D.C., NASA Lewis Research Center, March 1994.

${ }^{3}$ Moorehead, R.W., Deputy Director, Space Station Freedom Program and Operations, communication to Work Packages 1-4 Directors, dated April 3, 1992.

'Patterson, M.J., Hamley, J.A., Sarmiento, C.J., Manzella, D.H., Sarver-Verhey, T., Soulas, G.C., and Nelson, A., "Plasma Contactor Development for Space Station," IEPC-93-246, September 1993.

SPatterson, M.J., Hamley, J A., Sarver-Verhey, T., Soulas, G.C., Parkes, J., Ohlinger, W.L., Schaffner, M.S., and Nelson, A., "Plasma Contactor Technology for Space Station Freedom," AIAA Paper No. 93-2228, June 1993.

${ }^{6}$ Hamley, J.A., Hill, G., Patterson, M., Saggio, J., Terdan, F., and Mansell, J., "Development of a Power Electronics Unit for the Space Station Plasma Contactor," IEPC Paper No. 93-052, September 1993.

${ }^{7}$ Hamley, J.A. and Patterson, M.J., "Integration Testing of the Space Station Plasma Contactor Power Electronics
Unit," AIAA Paper No. 94-3307, June 1994.

${ }^{8}$ Sarver-Verhey, T., and Hamley, J.A., "Discharge Ignition Behavior of the Space Station Plasma Contactor," AIAA Paper No. 94-3311, June 1994.

'Soulas, G.C., "Hollow Cathode Heater Development for the Space Station Plasma Contactor," IEPC Paper No. 93-042, September, 1993.

${ }^{10}$ Kaufman, H.R., Advances in Electronics and Electron Devices, Vol. 36, Academic Press Inc., 1974.

"Sarver-Verhey, T.R., "Extended-Testing of Xenon Ion Thruster Hollow Cathodes," AIAA Paper No. 92-3204, July 1992.

${ }^{12}$ Sarver-Verhey, T.R., "Continuing Life-Test of a Xenon Hollow Cathode for a Space Plasma Contactor, AIAA Paper No. 94-3312, June 1994.

${ }^{13}$ Soulas, G., "Multiple Hollow Cathode Wear Testing for the Space Station Plasma Contactor," AIAA Paper No. 94-3310, June 1994.

${ }^{14}$ Soulas, G., "Hollow Cathode Heater Development for the Space Station Plasma Contactor," IEPC Paper No. 93042, September, 1993.

${ }^{15}$ Soulas, G., "Status of Hollow Cathode Heater Development for the Space Station Plasma Contactor, AIAA Paper No. 94-3309, June 1994. 
FUNCTIONAL TESTING OF THE SPACE STATION PLASMA CONTACTOR

Table 1 Plasma Contactor Subsystems

\begin{tabular}{|c|c|c|}
\hline subsystem & function & key technology issues \\
\hline $\begin{array}{l}\text { hollow cathode } \\
\text { assembly } \\
\{H C A\}\end{array}$ & $\begin{array}{l}\text { provides electron retum } \\
\text { current to control station } \\
\text { potential }\end{array}$ & $\begin{array}{l}\text { - long life and performance } \\
\text { - environmental effects on performance } \\
\text { - uncertainties in key parameters } \\
\text { - issues of scale }\end{array}$ \\
\hline $\begin{array}{l}\text { power electronics } \\
\text { unit } \\
\{\text { PEU }\}\end{array}$ & $\begin{array}{l}\text { provides command/control } \\
\text { and telemetry interface } \\
\text { converts } 120 \mathrm{VDC} \\
\text { station power to levels needed by } \\
\text { HCA and EMU } \\
\text { activates, ignites, and } \\
\text { maintains HCA operation } \\
\text { - detects and resolves faults }\end{array}$ & $\begin{array}{c}\text { - arc ignition and control } \\
\text { EM compatibility } \\
\text { - fault detection and resolution }\end{array}$ \\
\hline $\begin{array}{l}\text { expellant } \\
\text { management unit } \\
\{E M U\}\end{array}$ & $\begin{array}{l}\text { - provides regulated flow } \\
\text { of xenon gas to HCA }\end{array}$ & $\begin{array}{c}\text { - control of reactive contaminants } \\
\text { - flow control }\end{array}$ \\
\hline $\begin{array}{c}\text { orbit replaceable } \\
\text { unit } \\
\text { \{ORU\} }\end{array}$ & $\begin{array}{c}\text {-provides mechanical, } \\
\text { electrical, command/control } \\
\text { telemetry, and thermal interface } \\
\text { between contactor system and station } \\
\text { - provides micrometeroid } \\
\text { protection }\end{array}$ & - \\
\hline
\end{tabular}

Table 2 Space Station Engineering Model HCA Attributes

\begin{tabular}{|c|c|}
\hline $\begin{array}{l}\text { Design } \\
\text { - enclosed-keeper geometry } \\
\text { - hollow cathode with low-work function electron emit- } \\
\text { ter }\end{array}$ & $\begin{array}{l}\text { Mechanical Characteristics } \\
\text { - mass: } 125 \mathrm{~g}(4.4 \mathrm{oz} \text {.) } \\
\text { - parts count: } 30 \\
\text { - shape: cylindrical } \\
\text { - size/vol.: } 11.5 \mathrm{~cm} \text { length } \times 2.8 \mathrm{~cm} \mathrm{dia.} / 71 \mathrm{~cm}^{3}\end{array}$ \\
\hline $\begin{array}{l}\text { Performance } \\
\text { - maximum electron emission current: } 10 \mathrm{~A} \\
\text { - input power \{typical\} } \\
\text { - ignition/heater power: } \\
54.7 \mathrm{~W}\{7.2 \mathrm{~A} @ 7.7 \mathrm{~V}\} \\
\text { - steady-state operation } / \mathrm{keeper} \text { power: } \\
28 \mathrm{~W}\{2.0 \mathrm{~A} @ 14 \mathrm{~V}\} \text { idle mode } \\
\text { - expellant: xenon } \\
\text { - xenon consumption rate }\{\text { typical\}: } 18.6 \mathrm{~kg} / \mathrm{yr} \text {, } \\
6.0 \text { sccm } \\
\text { - lifetime: } 17,500 \mathrm{~h} \text { expected }\end{array}$ & $\begin{array}{l}\text { Interfaces } \\
\text { - mechanical attachment to ORU box } \\
\text { - single expellant feed line to EMU } \\
\text { - 3-pin electrical connector to PEU } \\
\text { Development Status } \\
\text { - prototype test program completed } \\
\text { - engineering model completed and in testing }\end{array}$ \\
\hline
\end{tabular}




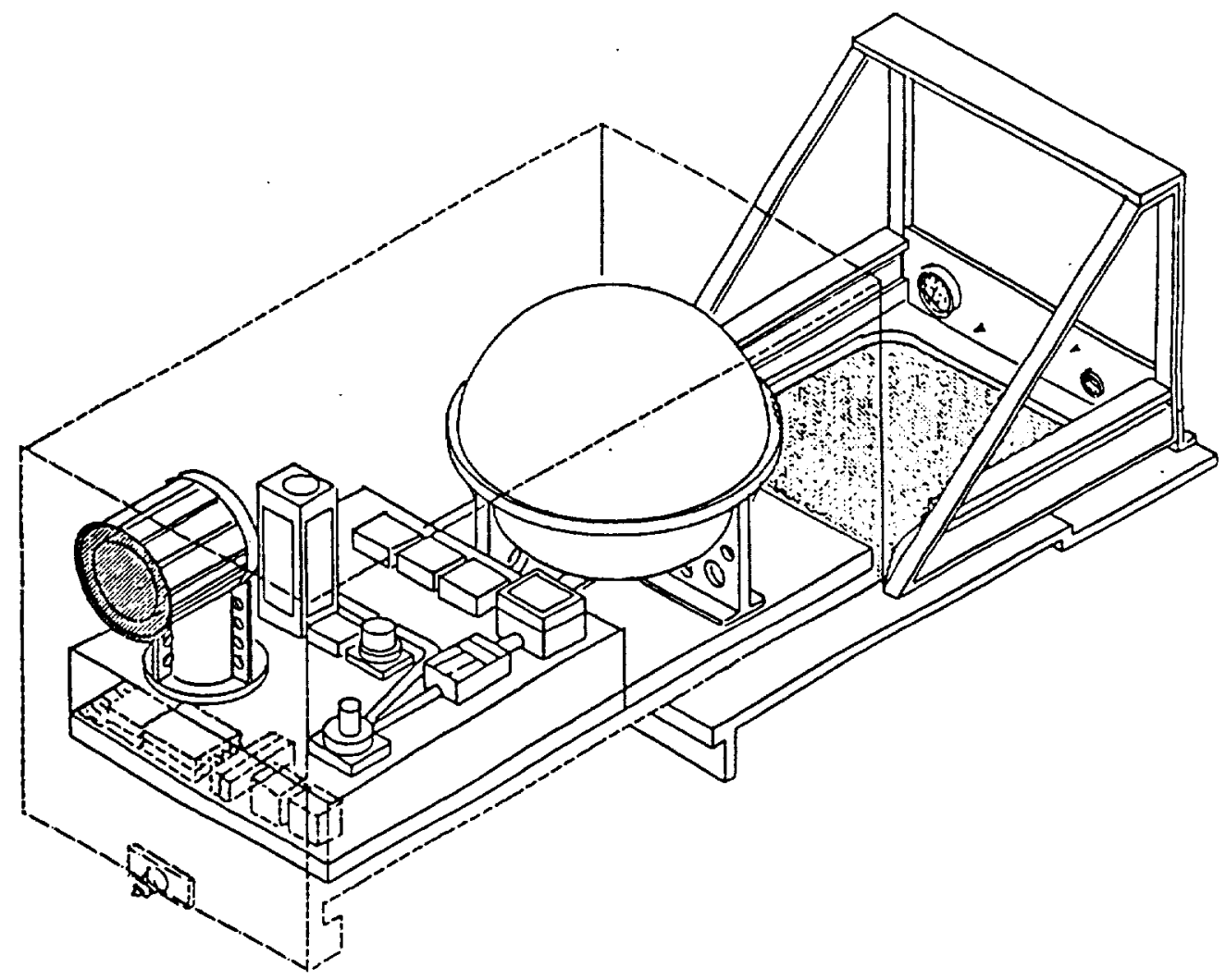

Fig. 1 Space station plasma contactor system conceptual design.

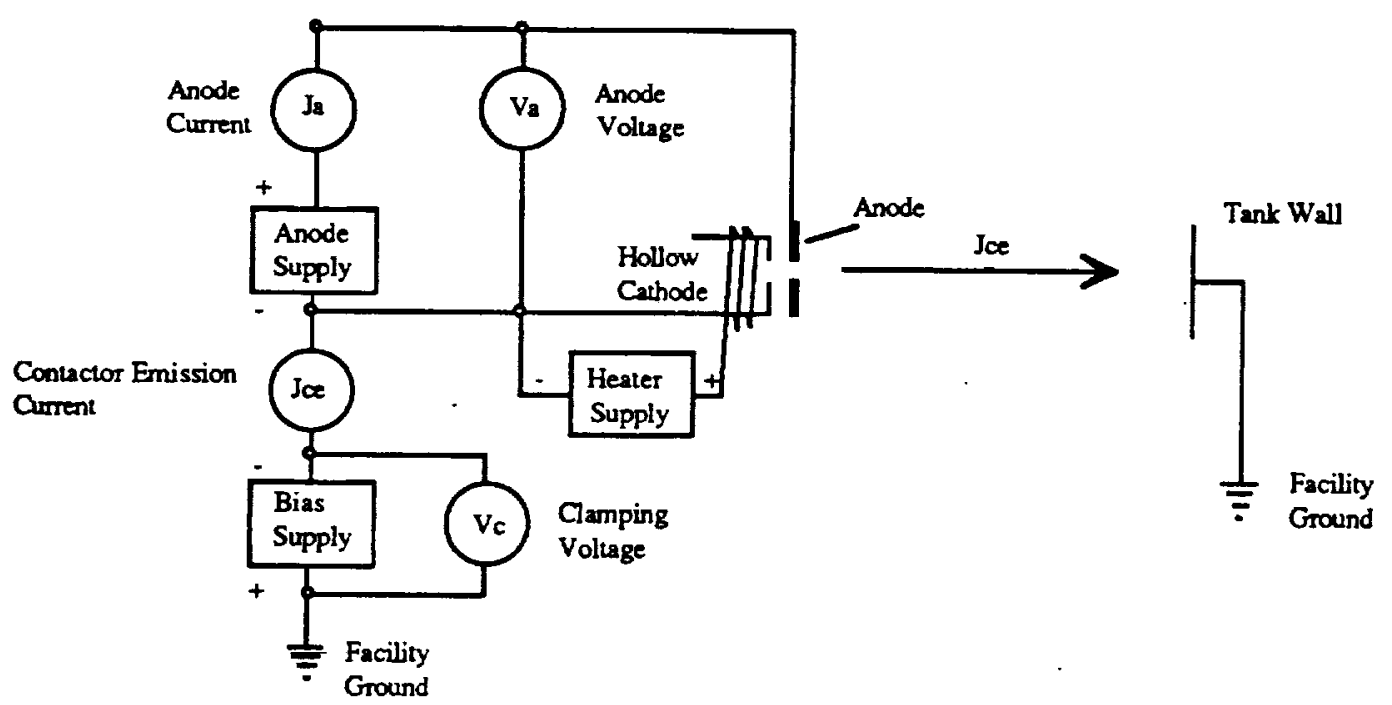

Fig. 2 Electrical test configuration for HCA. 


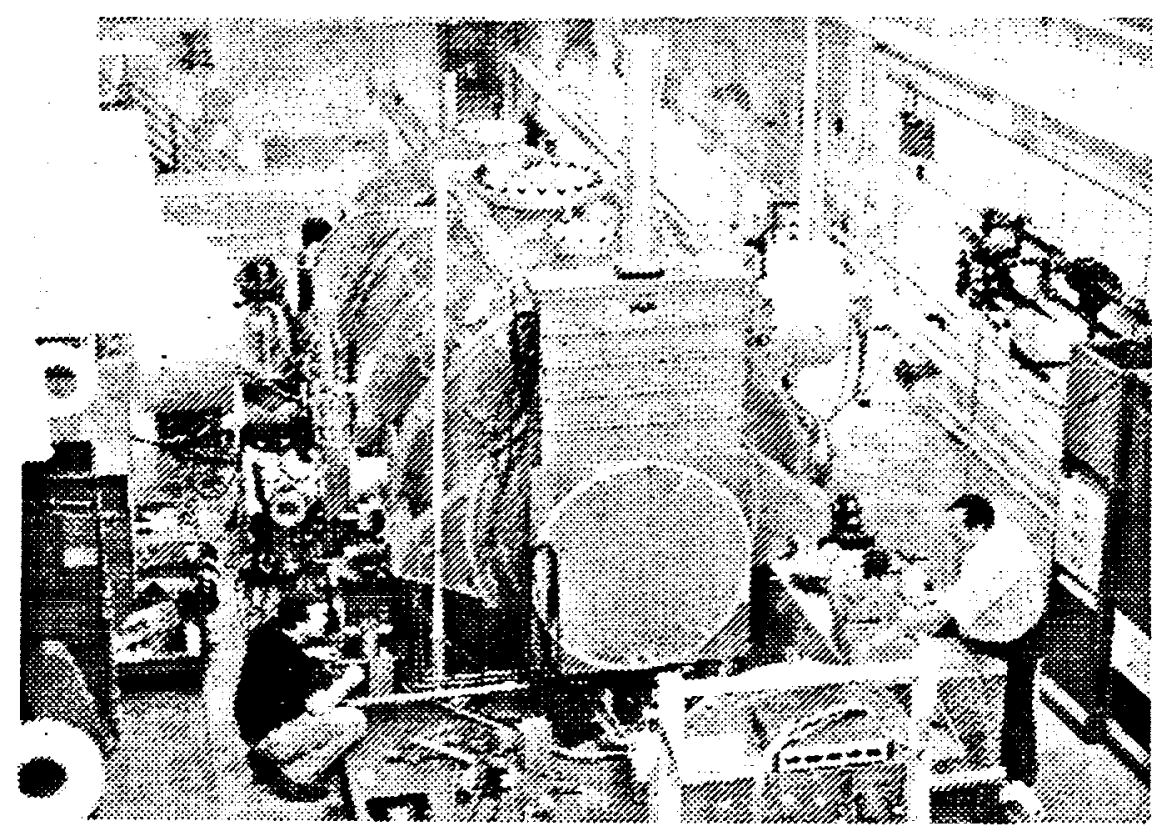

Fig. 3 Plasma contactor system integration test stand.

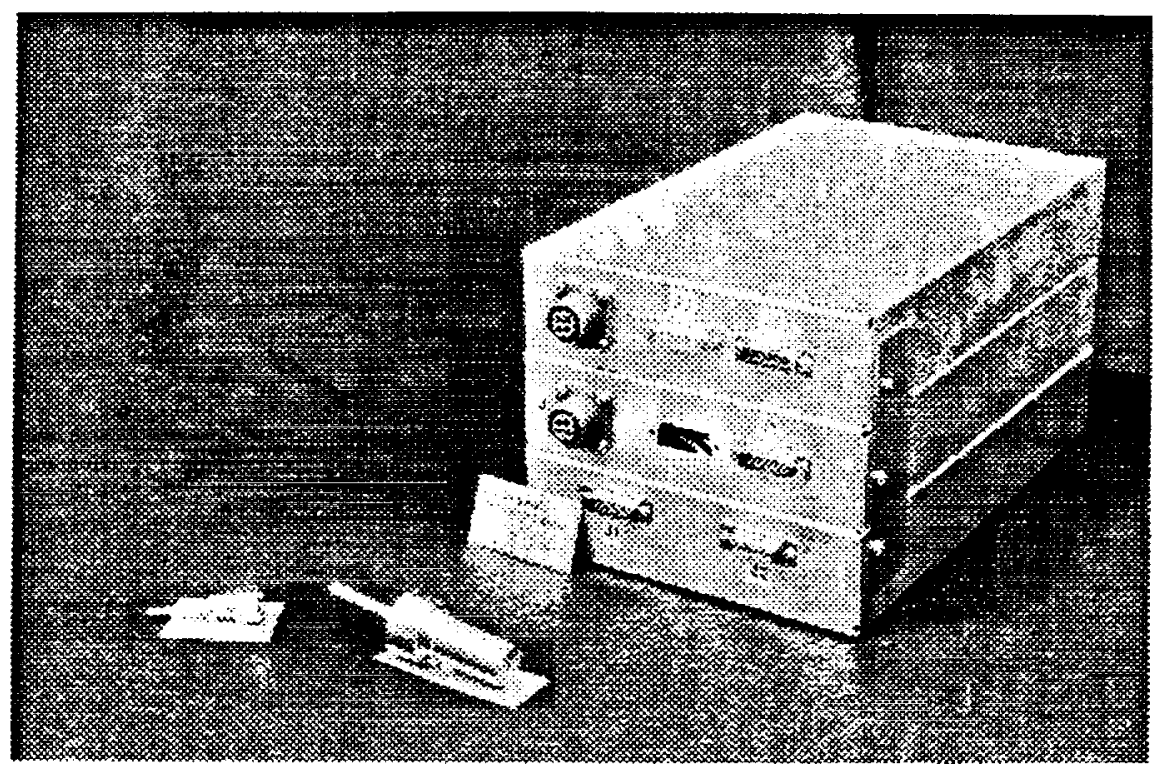

Fig. 4 Breadboard power electronics unit and engineering model HCA. 


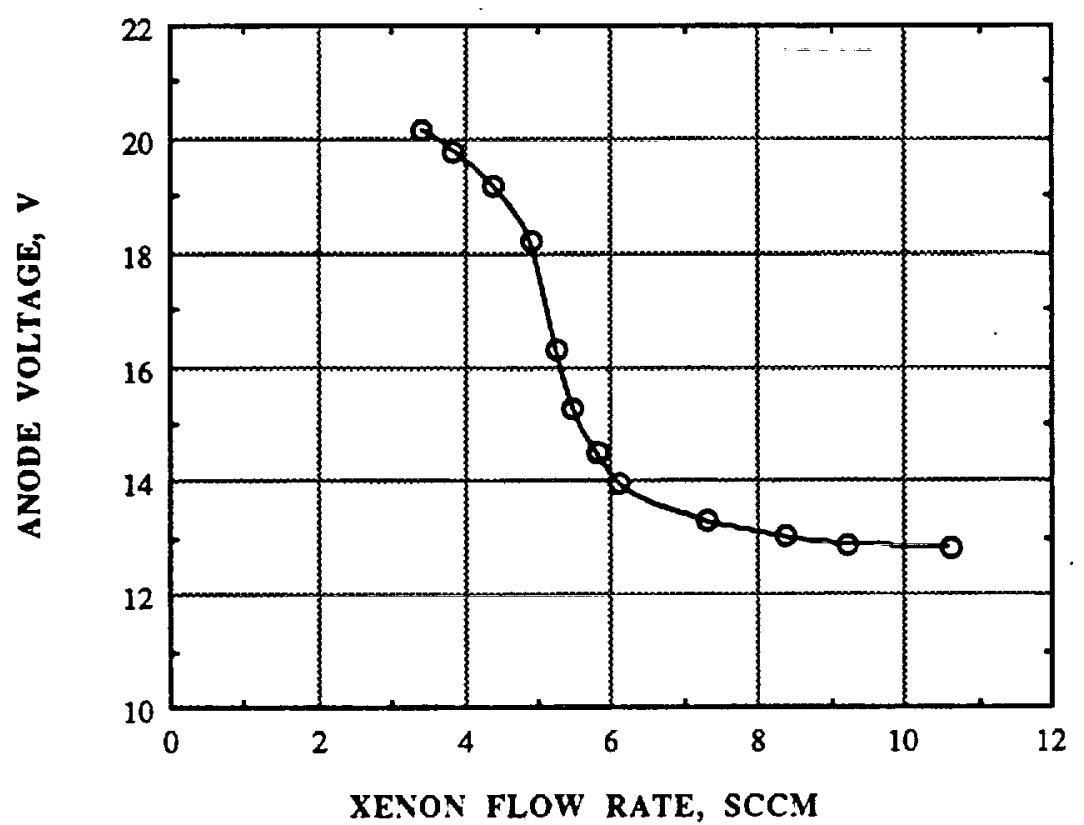

Fig. 5 HCA variation in anode voltage with xenon flow rate; $2.0 \mathrm{~A}$ anode current.

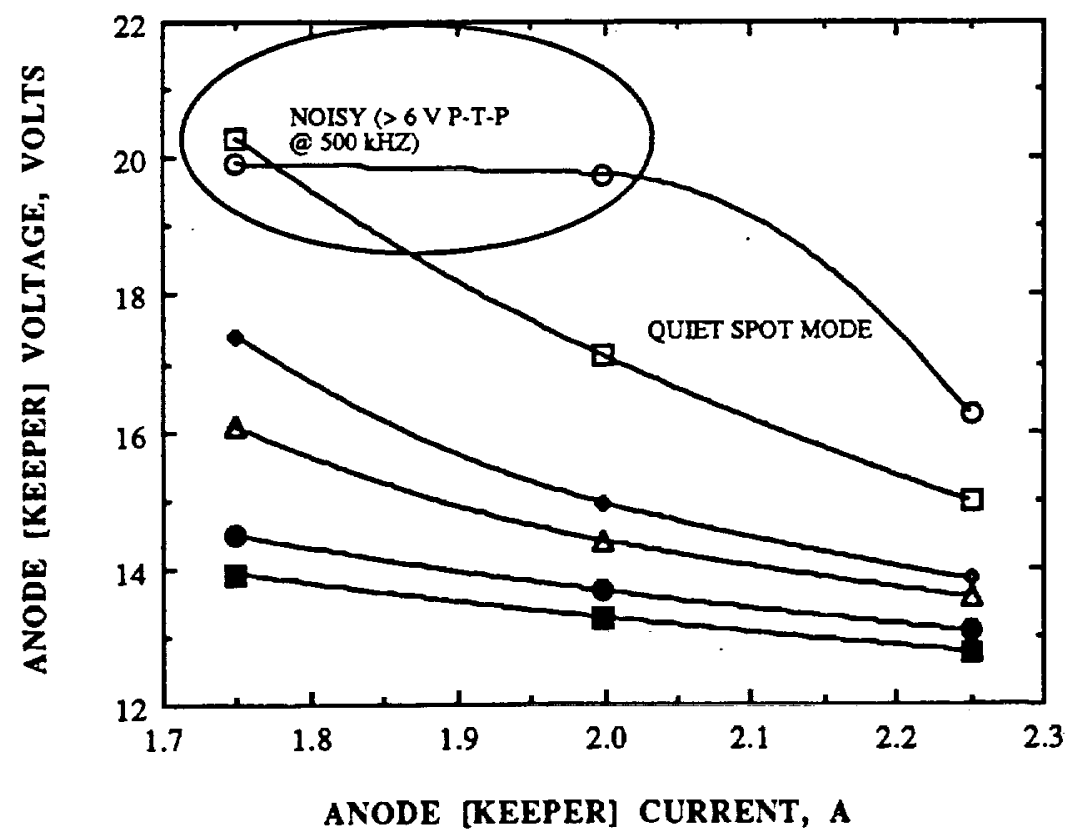

- $5.0 \mathrm{SCCM}$

D $5.2 \mathrm{SCCM}$

- $5.6 \mathrm{SCCM}$

$\triangle 5.8 \mathrm{SCCM}$

- $6.5 \mathrm{SCCM}$

- $7.5 \mathrm{SCCM}$

Fig. 6 HCA variation in anode voltage with anode current, for several xenon flow rates. 


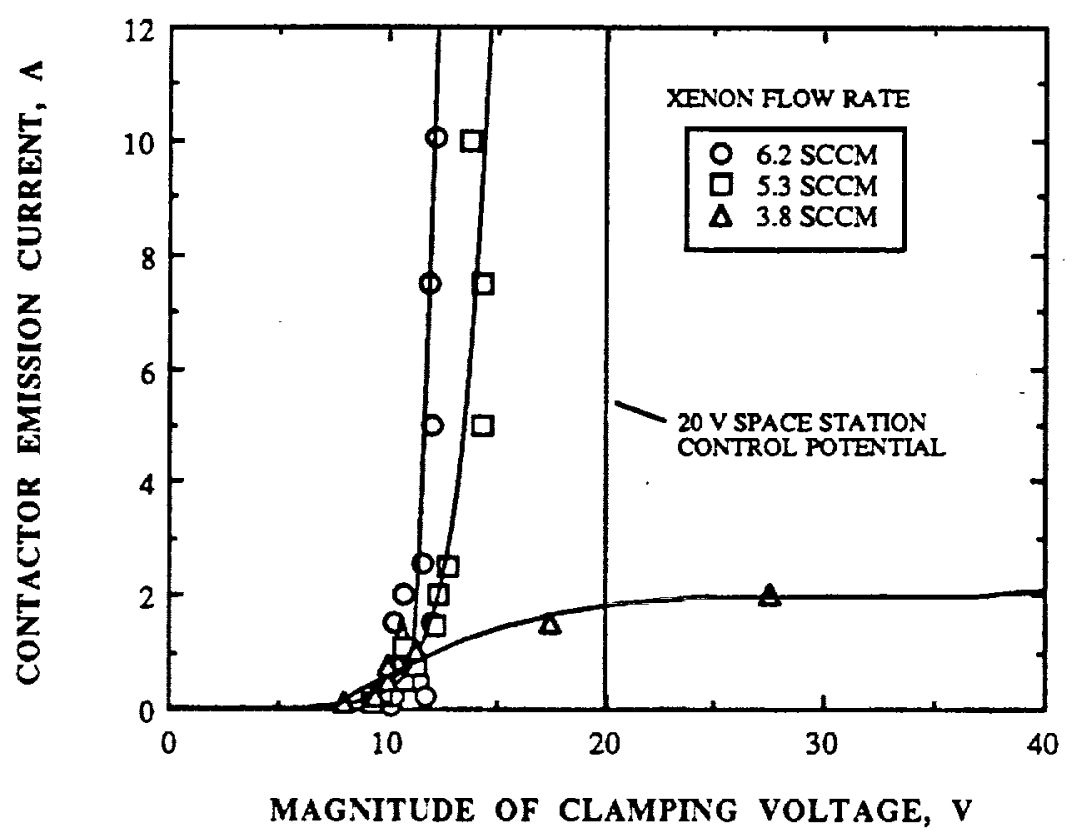

Fig. 7 HCA contactor emission characteristics for various xenon flow rates.

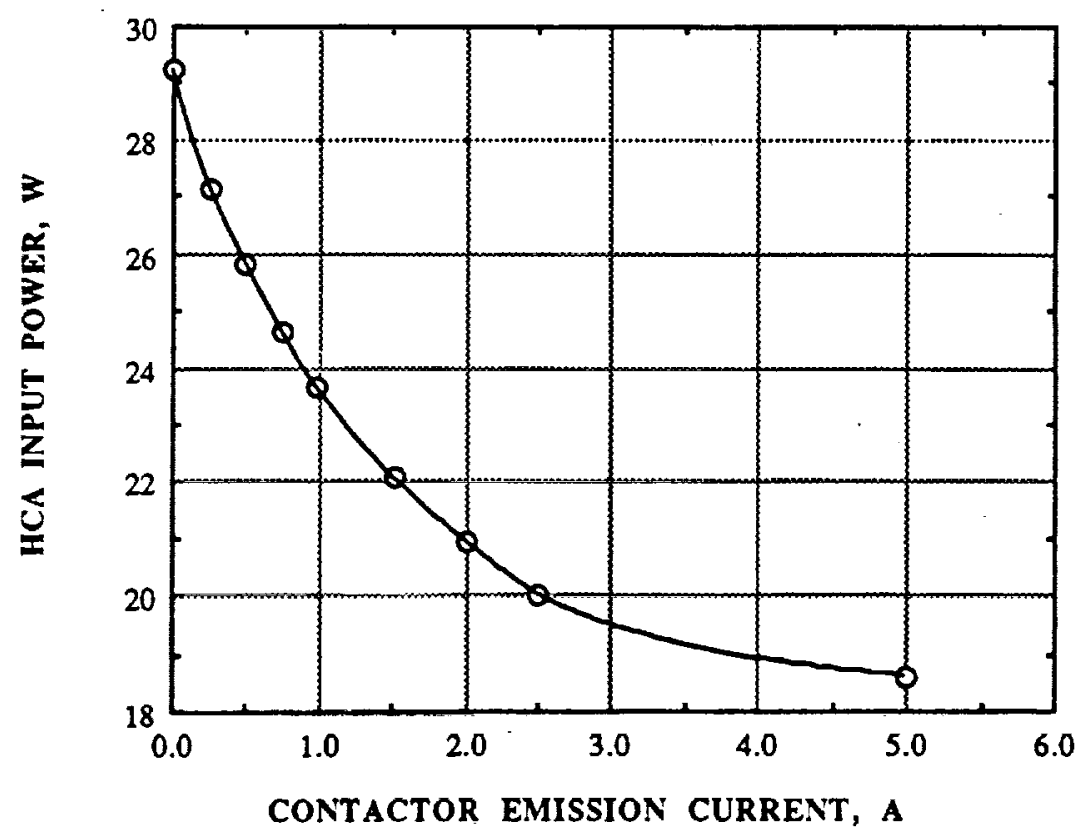

Fig. 8 HCA variation in input power versus contactor emission current. 


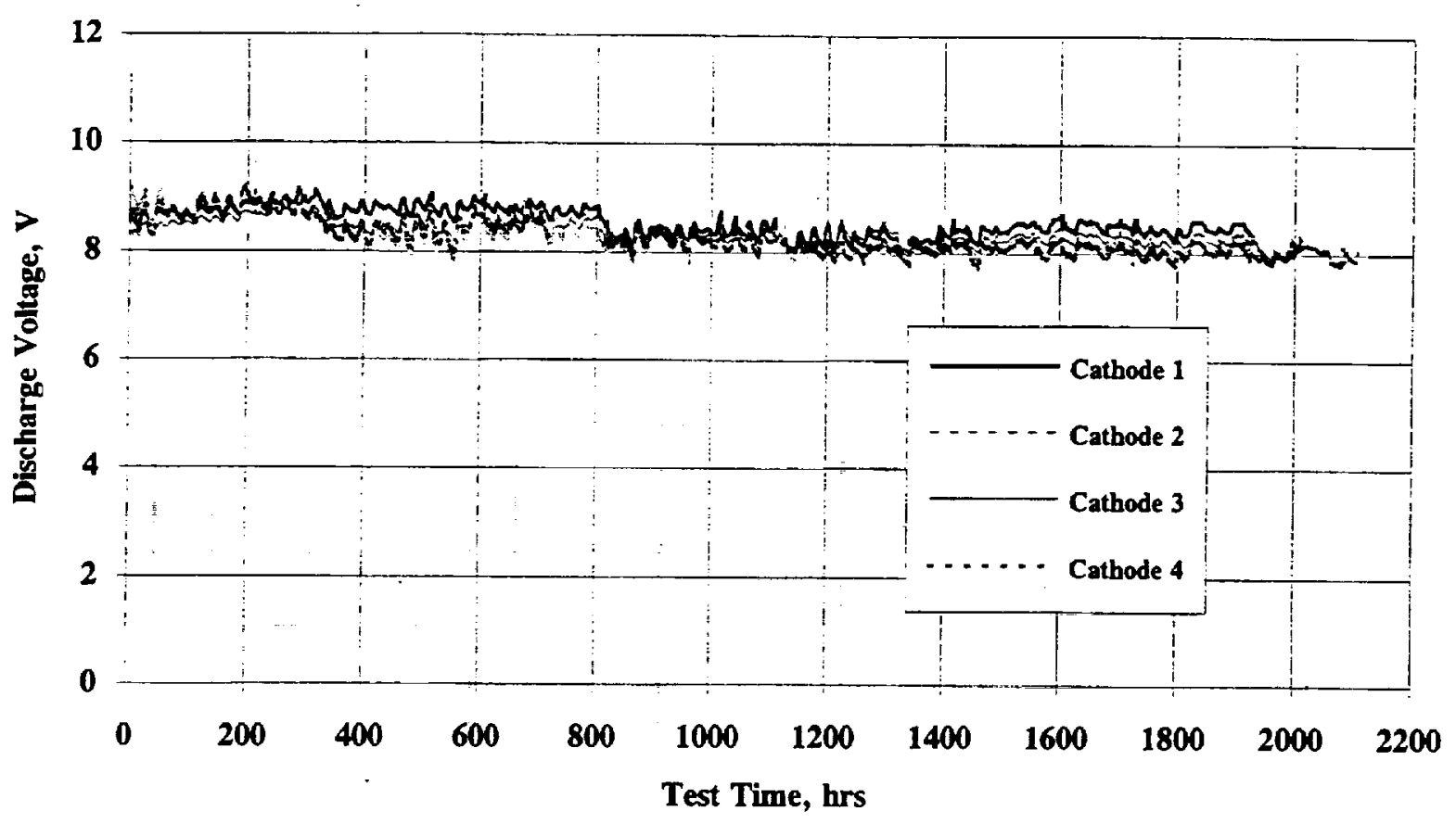

Fig. 9 Electrode voltage versus time for several hollow cathodes; from Ref. 13.

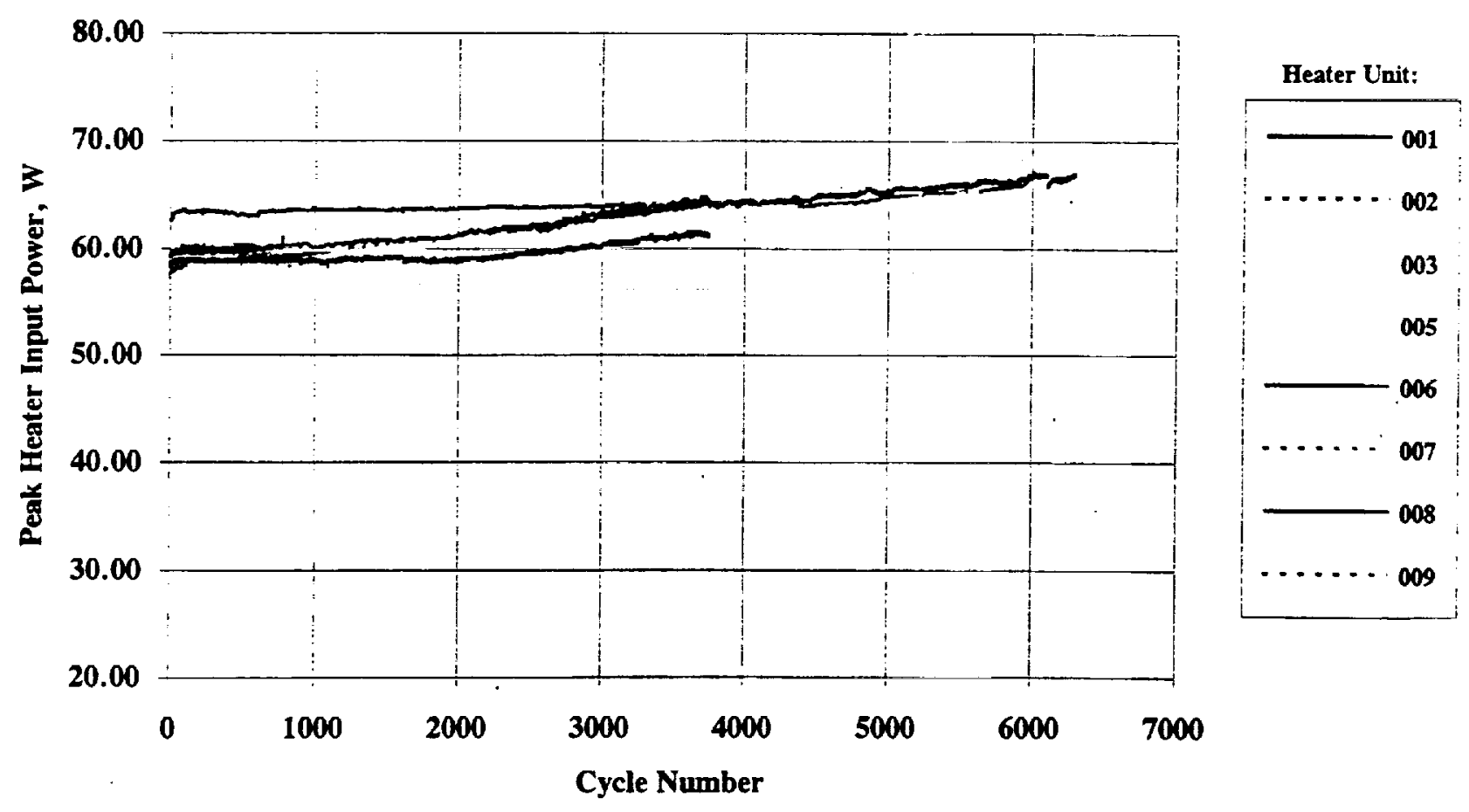

Fig. 10 Variation in maximum heater input power versus cycle number for several heaters, from Ref. 15. 


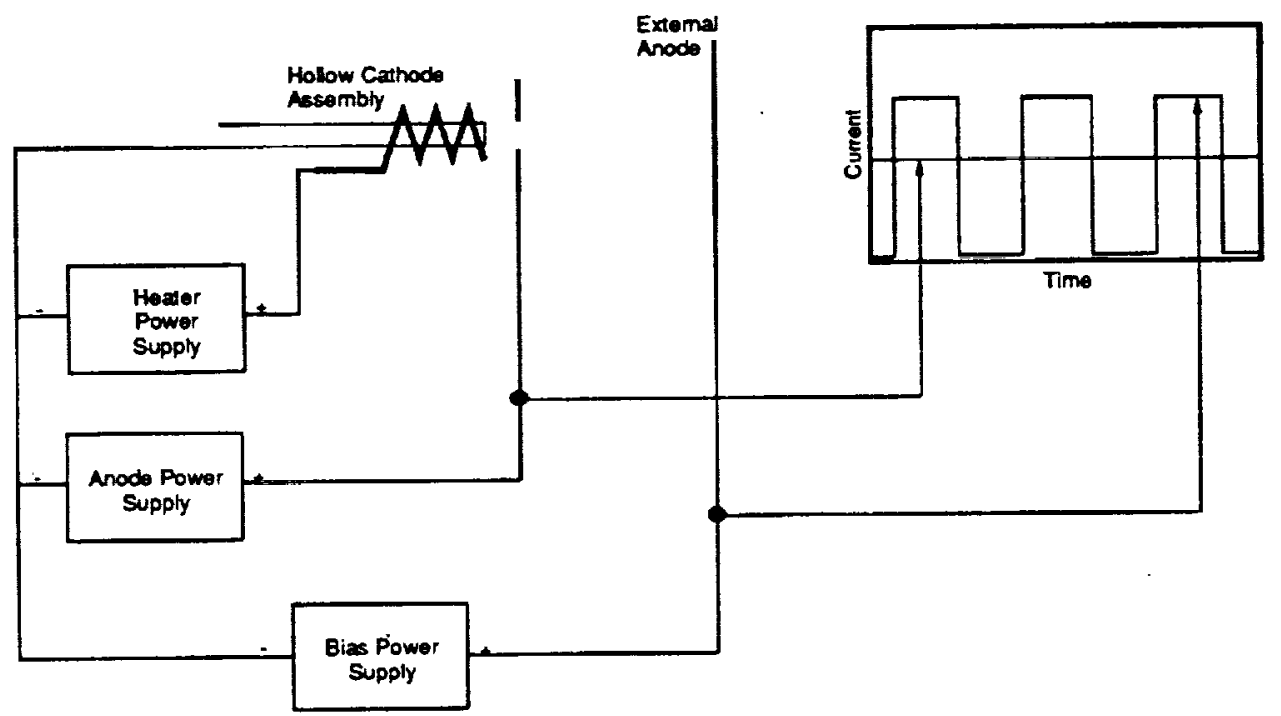

Fig. 11 Electrical schematic for HCA lifetesting. 
Public reporting burden for this collection of information is estimated 10 average 1 hour per response, including the time for reviewing instructions, searching existing data sources, gathering and maintaining the data needed. and completing and reviewing the collection of information. Send comments regarding this burden estimate of any other aspect of this collection of information, including suggestions for reducing this burden, to Washington Headquarters Services, Directorate for Intormation Operations and Reports. 1215 Jellerson Davis Highway. Sutte 1204. Arlington, VA 22202-4302, and to the Ottice of Managerrent and Budget. Papenwork Reduction Project (0704-0188). Washington. DC 20503.
1. AGENCY USE ONLY (Leave blank)
2. REPORT DATE
March 1995
3. REPORT TYPE AND DATES COVERED
Technical Memorandum

\section{TITLE AND SUBTTILE}

Functional Testing of the Space Station Plasma Contactor

6. $A U T H O R(S)$

Michael J. Patterson, John A. Hamley, Timothy R. Sarver-Verhey, and George C. Soulas

7. PERFORMING ORGANIZATION NAME(S) AND ADDRESS(ES)

National Aeronautics and Space Administration

Lewis Research Center

Cleveland, Ohio 44135-3191

9. SPONSORING/MONITORING AGENCY NAME(S) AND ADDRESS(ES)

National Aeronautics and Space Administration

Washington, D.C. 20546-0001
5. FUNDING NUMBERS

WU-478-43-10

8. PERFORMING ORGANIZATION REPORT NUMEER

E-9405

10. SPONSORINGMONITORING AGENCY REPORT NUMBER

NASA TM-106841

AIAA-94-3308

11. SUPPLEMENTARY NOTES

Prepared for the 30th Joint Propulsion conference cosponsored by AIAA, ASME, SAE, and ASEE, Indianapolis, Indiana, June 27-29, 1994.

Michael J. Parterson and John A. Hamley, NASA Lewis Research Center; Timothy R. Sarver-Verhey and George C. Soulas, NYMA, Inc., Engineering Services Division, 2001 Aerospace Parkway, Brook Park, Ohio 44142 (work funded by NASA Contract NAS3-27186). Responsible person, Michael J. Patterson, organization code 5330, (216) 433-7481.

12a. DISTRIBUTION/AVAILABILTY STATEMENT

12b. DISTRIBUTION CODE

Unclassified - Unlimited

Subject Category 20

This publication is available from the NASA Center for Aerospace Information, (301) 621-0390.

13. ABSTRACT (Maximum 200 words)

A plasma contactor system has been baselined for the Intemational Space Station Alpha (ISSA) to control the electrical potentials of surfaces to eliminate/mitigate damaging interactions with the space environment. The system represents a dual-use technology which is a direct outgrowth of the NASA electric propulsion program and, in particular, the technology development effort on ion thruster systems. The plasma contactor subsystems include a hollow cathode assembly, a power electronics unit, and an expellant management unit. Under a pre-flight development program these subsystems are being developed to the level of maturity appropriate for transfer to U.S. industry for final development. Development efforts for the hollow cathode assembly include design selection and refinement, validating its required lifetime, and quantifying the cathode performance and interface specifications. To date, cathode components have demonstrated over 10,000 hours lifetime, and a hollow cathode assembly has demonstrated over 3,000 ignitions. Additionally, preliminary integration testing of a hollow cathode assembly with a breadboard power electronics unit has been completed. This paper discusses test results and the development status of the plasma contactor subsystems for ISSA, and in particular, the hollow cathode assembly.

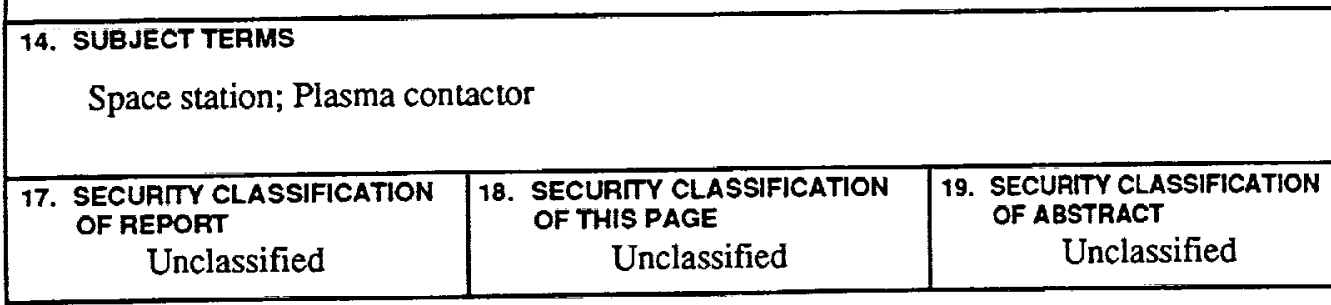




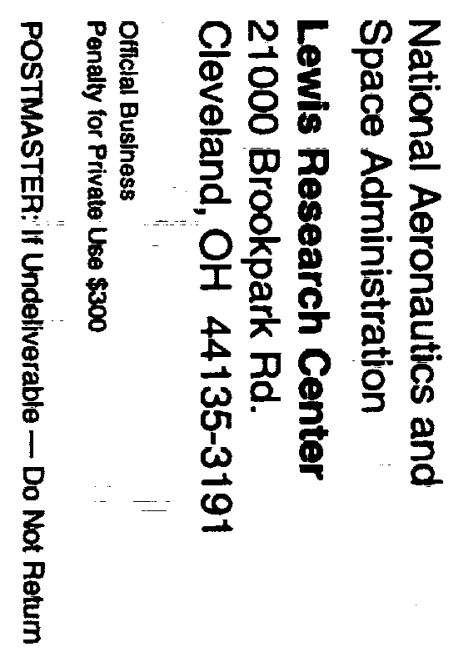


